\title{
Anthropometric Profile and Nutritional Status in Elderly: A Cross- Sectional Study
}

\author{
Zeynel Abidin Erbesler, Tufan Ulcay
}

Ahi Evran University Turkey

\begin{abstract}
Background: Various screening tools are used to identify elderly individuals who are malnourished or at risk for malnutrition based on their nutritional status. Anthropometric measurements are important indicators of an individual's nutritional status. In this study, we aimed to establish anthropometric standards for the Turkish elderly population and to investigate any significant relationship between anthropometric characteristics and nutritional status.

Materials and Methods: Age, sex, weight, height, waist-to-hipratio (WHR) and body massindex (BMI) were recorded. We also administered the Mini Nutritional Assessment (MNA) and a hand grip test.

Results: In our study, $72 \%$ of males and $84 \%$ of females were in the overweight group, $24 \%$ of males and $16 \%$ of females were in the normal weight group, and only $4 \%$ of males were in theweak group. For males, $76 \%$ were not at risk for malnutrition, $20 \%$ were at risk, and $4 \%$ were determined to have malnutrition. For females, $68 \%$ were not at risk for malnutrition, and $32 \%$ were at risk. There were no females who had malnutrition. With regard to muscle strength, $80 \%$ of males and $92 \%$ of females did not have sufficient strength. Weight, grip strength and WHR were significantly related to MNA ( $p<0.05)$.

Conclusion: We provided sex-specific distributions for many anthropometric measurements for the elderly which can be used as reference values for the Turkish elderly population to identify individuals at greater risk for nutritional disorders.
\end{abstract}

Keywords: Anthropometry, Nutrition, Elderly

\section{Introduction}

Ageing is defined as the gradual reduction in vital function and ability to adapt to environmental factors, causing reduced productivity and alterations in the body composition, organ function and adequate energy intake (Saka et al. 2010). The ageing process involves physiological and nutritional changes that manifest in loss of height, weight and muscle mass, as well as an increase in fat mass. Also, the adipose tissue is redistributed with ageing, with fat accumulation in the trunk and viscera (García et al. 2007, Perissinotto et al. 2002). The elderly population is defined by the World Health Organization (WHO) as individuals 65 years of age and is increasing by 5\% annually in both developed and developing countries (Pieterse et al. 2002, Guigoz et al. 1996, Karakaş et al. 2012). Turkey is one of such countries with a rapidly increasing number of aged individuals in recent years. People aged 65 and over comprise $3.9 \%$ of the total population in 1935 and have steadily increased since: 5.7\% in 2000, 7.7\% in 2013 and 8.3\% in 2016. It is expected that the aged population will rise to $10.2 \%$ in 2023 and $17.2 \%$ in 2050 (Karakaş et al. 2012, Republic of TurkeyMinistry of Health 2016).

A close relationship has been established between nutritional status and health. The homeostasis of body composition and function determines the health status through the exchange of energy and nutrients with the environment (Donini et al. 2013). Malnutrition is a frequent condition that is widely represented in the geriatric population and underestimated in diagnostic and therapeutic work-up; malnutrition is known to affect the health status and life expectancy of elderly people (Vetta et al. 1999). Nutritional assessments can determine if an elderly individual is in a state of malnutrition, overweight and early obesity (Rodrigues et al. 2014). 
Various screening tools are used to identify elderly individuals who are malnourished or at risk for malnutrition based on their nutritional status. Between 1998 and 2002, 71 screening tests were developed, of which 21 were applicable to elderly individuals. The Mini Nutritional Assessment (MNA) is a frequently used tools which has been shown to be reliable and valid in determining the nutritional status of elderly individuals (Başıüyük et al. 2017).

Anthropometric measurements are now regarded as important indicators of an individual's nutritional status. Malnutrition, either undernutrition or overnutrition, causes detrimental alterations of body composition (Rahman et al. 1998). Anthropometric measurements used to assess the elderly are usually easy to obtain and are both non-invasive and inexpensive. The main measurements are body weight, height, girth and skin fold thickness (Milanović et al. 2011). Body mass index (BMI) is frequently used as an indicator of nutritional status and is an important predictor of mortality and activities of daily living decline among older people. Anthropometric measurements of the mid-upper arm are often performed for measuring body composition because they are a quick, inexpensive and non-invasive way of measuring nutritional status. The triceps skinfold (TSF) thickness reflects subcutaneous fat, whereas mid-arm circumference (MAC) takes into account the humeral diameter, skeletal muscles and fat covering the limb, therefore reflecting the changes in lean body mass and fat. Mid-upper-arm muscular circumference and arm muscle area, which are derived from MAC and TSF, are also useful indicators of muscle mass (Enoki et al. 2007).

There is a need to establish appropriate anthropometric reference data to evaluate the nutritional assessments of the elderly as there have been only a few studies of nutritional status in the elderly using anthropometric data in Turkey. Thus, there is limited knowledge of the relationships among body circumferences, subcutaneous adipose tissue thicknesses and total body fat in the elderly.

The American Society of Anesthesiologists' (ASA) classification of Physical Health is a widely used grading system for the preoperative health of surgical patients. The ASA score is a subjective assessment of a patient's overall health that is based on five classes (I to V): (I) patient is a completely healthy fit patient, (II) patient has mild systemic disease, (III) patient has severe systemic disease that is not incapacitating, (IV) patient has incapacitating disease that is a constant threat to life and (V) a moribund patient who is not expected to live $24 \mathrm{~h}$ with or without surgery (Daabiss 2011).

This study aimed to contribute to the formation of anthropometric standards for the Turkish elderly population. Our goal was to investigate any significant relationships between anthropometric characteristics and nutritional status of 200 patients classified as an ASA I-II group over 65 years presenting to our anaesthesia outpatient clinic.

\section{Materials and Methods}

The study was approved by the ethics committee of Ahi Evran University (Ethical Approval Date:27/02/2018, Number: 2018-04/43). The exclusion criteria were the following: patients in whom we were unable to measure height and weight, hemiplegia, oedema around the arm or calf, inability to perform the tests and questionnaires, dementia, Parkinson's disease, history of previous cerebrovascular event, hand function limitation and gait disturbance. Written informed consent was given by all 200 participants (100 males and 100 females) after explanation of the protocols, prior to enrolment in the study.

Patients' age, sex, weight, height and BMI values were recorded by the same researcher who administered the MNA. Patients were classified according to their BMI: >27, overweight; 27-22, normal weight; and $<22$, underweight.

For the MNA, if the total MNA score is $\geq 24$, there is no risk for malnutrition. A score of $17-23.5$ points indicates malnutrition risk, and $<17$ indicates protein energy malnutrition.

Hand grip tests were performed using a digital hand dynamometer (Smedley Digital Hand Dynamometer) to assess muscle power. Patients were placed on a chair, their hands were placed on a table, and their arms were held at $90^{\circ}$ of flexion parallel to the floor. Measurements were taken three times on the dominant hand, with 1-min rest periods. The standards of hand grip strength may vary according to race and age. The latest report from the European Working Group on Sarcopenia in the Older People (EWGSOP) has identified the hand grip strength cut-off points to be 20 and $30 \mathrm{~kg}$ for women and men, respectively.

MAC and calf circumference, waist circumference, hip circumference and TSF thickness measurements were performed by the same investigator who administered the MNA. TSF thickness measurements were taken vertically from the midpoint of the distance between the acromion and olecranon while the arm was relaxed next to the body. The waist and hip circumference measurements, expressed in centimetres, were 
performed using a measuring tape. Measurement of waist circumference crossed the umbilicus line. The hip circumference was the measurement across the widest region of the hip. Waist-to-hip circumference ratio (WHR) was calculated. It is suggested by the WHO that the healthy waist circumference values are $<94 \mathrm{~cm}$ in males and $<80 \mathrm{~cm}$ in females. Values between 94 and $102 \mathrm{~cm}$ in males and between 80 and $88 \mathrm{~cm}$ in females are considered 'at risk', and $\geq 102 \mathrm{~cm}$ in men and $\geq 88 \mathrm{~cm}$ in women are considered 'high-risk'. The healthy WHR values as defined by the WHO are $<0.90$ for males and $<0.85$ for females; as such.

Relationships between the nutritional status and anthropometric measurements of individuals were also investigated.

All data were analysed using IBM SPSS V23. The normality of the measurements was examined using the Kolmogorov-Smirnov and Shapiro-Wilk normality tests. Independent t-test was used for sex comparison of the nutritional status and anthropometric measurements of elderly subjects. Correlation test was used to determine the relationship between the nutritional status and anthropometric measurements of individuals.

\section{Results}

The overall mean age was 74,2 $\pm 6,71$ for females and 78,2 $\pm 7,31$ for males. The anthropometric values according to gender are shown in Table 1. Sex comparisons showed that height, waist-to-hip ratio (WHR) and grip strength were greater in males, whereas BMI, hip circumference and MAC were greater in females $(p<0,05)$. Males and females did not differ in terms of weight, waist circumference and triceps skinfold thickness.

In our study, $72 \%$ of male participants and $84 \%$ of female participants were in the overweight group. $24 \%$ of males and $16 \%$ of females were in the normal weight group, whereas only $4 \%$ of males were in the weak group. The mean BMI values were high in both women and men and were in overweight groups (Table 1).

Table 1: Anthropometric measurements according to the gender

\begin{tabular}{|c|c|c|c|}
\hline PARAMETERS & $\begin{array}{c}\text { MALE }(\mathrm{n}=100) \\
\text { Mean } \pm \text { SD }(\text { Min-Max })\end{array}$ & $\begin{array}{c}\text { FEMALE }(\mathrm{n}=100) \\
\text { Mean } \pm \text { SD }(\text { Min-Max })\end{array}$ & P Value \\
\hline Weight (kg) & $76.56 \pm 14.16(53.0-115.0)$ & $75.20 \pm 14.04(56.0-112.0)$ & $p>0,05$ \\
\hline Height $(\mathrm{cm})$ & $163.06 \pm 4.85(151.5-181.0)$ & $151.0 \pm 3.99(141.0-159.5)$ & $\mathrm{p}<0,05$ \\
\hline BMI $\left(\mathrm{kg} / \mathrm{cm}^{2}\right)$ & $27.59 \pm 2.76(21.2-37.09)$ & $30.99 \pm 3.99(25.2-48.2)$ & $\mathrm{p}<0,05$ \\
\hline Waist Circumference $(\mathrm{cm})$ & $103.55 \pm 9.14(83.0-118.0)$ & $100.93 \pm 8.59(86.0-115.0)$ & $\mathrm{p}>0,05$ \\
\hline Hip Circumference $(\mathrm{cm})$ & $103.72 \pm 5.78(95.0-124.0)$ & $112.5 \pm 7.44(95.0-121.0)$ & $\mathrm{p}<0,05$ \\
\hline Waist-to-Hip Ratio (WHR) & $0.97 \pm 0.055(0.87-1.11)$ & $0.91 \pm 0.054(0.85-1.02)$ & $\mathrm{p}<0,05$ \\
\hline $\begin{array}{l}\text { Mid-arm Circumference } \\
(\mathrm{MAC})(\mathrm{cm})\end{array}$ & $29.78 \pm 2.95(23.0-34.0)$ & $32.77 \pm 4.13(24.0-39.0)$ & $\mathrm{p}<0,05$ \\
\hline $\begin{array}{l}\text { Triceps Skinfold (TSF) } \\
\text { Thickness (mm) }\end{array}$ & $30.56 \pm 13.51(11.5-65.5)$ & $25.54 \pm 6.71(16.0-38.5)$ & $\mathrm{p}>0,05$ \\
\hline Grip Strength (kg) & $24.10 \pm 7,32(9.6-37.6)$ & $10.45 \pm 5.03(5.0-21.6)$ & $\mathrm{p}<0,05$ \\
\hline
\end{tabular}

In our study, $76 \%$ of male participants are not at risk for malnutrition, $20 \%$ of male participants are in the risk group, and $4 \%$ have malnutrition. Although $68 \%$ of the female participants are not at risk for malnutrition, $32 \%$ are in the risk group. Women do not have malnutrition (Figure 1).

According to the EWGSOP, $80 \%$ of male participants and $92 \%$ of female participants do not have sufficient muscle strength. Also, the average muscle strength of both men and women is not sufficient (Table 1).

In terms of waist circumference measurement, according to the criteria of the WHO, $24 \%$ of the male participants in our study were in the risk group, and 52\% were in the high-risk group. Of the 100 women participants, $12 \%$ were in the risk group, and $88 \%$ were in the high-risk group. Also, the average waist circumference values of both men and women were in the high-risk group (Table 1).

According to the WHO criteria, $8 \%$ of the male participants and $4 \%$ of the female participants are in the healthy group in terms of WHR. A large proportion of both men and women were in the risk group for this ratio. In addition, the average WHR values both in men and women were above the limits determined by the WHO (Table 1). 
In addition, the correlation between the anthropometric measurements and MNA was also investigated. Only the weight, grip strength and WHR were found to have a positive, significant and weak correlation with MNA ( $\mathrm{p}<0.05)$. There was a weak positive correlation between weight and MNA $(\mathrm{r}=0.31, \mathrm{p}<0.05)$, a weak positive correlation between grip strength and MNA $(r=0.31, p<0,05)$ and a weak positive correlation between WHR and MNA $(r=0.28, \mathrm{p}<0.05)$.

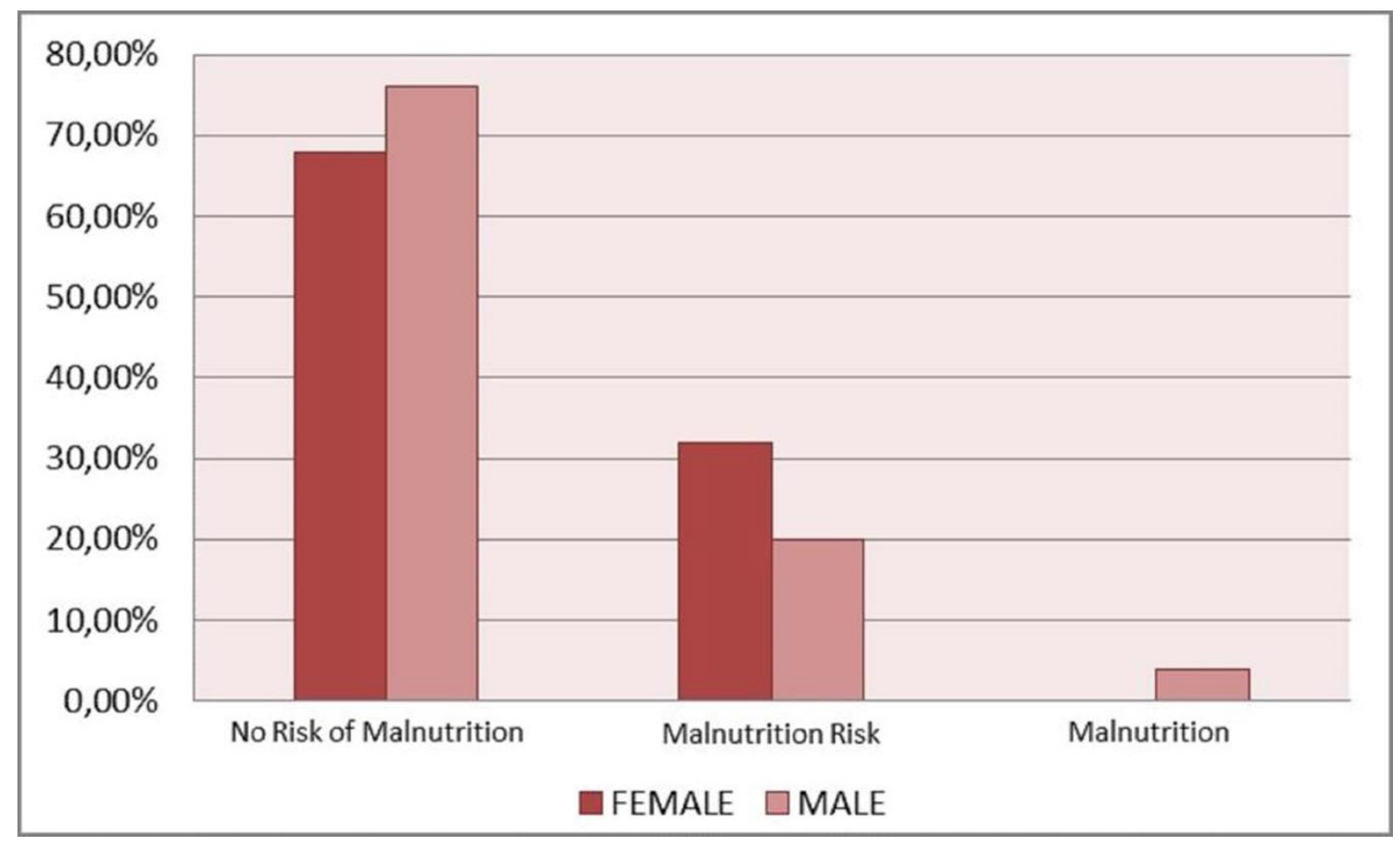

Figure 1: Nutrition risk distribution

\section{Discussion}

In general, body mass increases during adulthood and decreases progressively with old age at a rate of approximately $1 \mathrm{~kg}$ per decade. Furthermore, during old age, height is estimated to decrease at $0.5-1.5 \mathrm{~cm}$ per decade. Mean weight and height are both greater in men than in women, but both gradually decrease with age in both men and women. Also, the skeletal system undergoes structural modifications such as demineralisation, which reduces the width of the vertebrae and deforms the long bones of the inferior extremities (García et al. 2007).

Anthropometry and other body measurements are basic components of screening tools to determine the nutritional status in the elderly. BMI is most frequently used to identify subjects at risk for being under- and overweight (Narancic et al. 2013). The Malnutrition Advisory Group, suggested that BMI is a simple and reproducible measure for assessing malnutrition in older subjects. Also, the WHO reports that BMI cut-off values vary between ethnic groups (Bahat et al. 2012). In our study, females had significantly greater BMI than males, consistent with previous studies (García et al. 2007, Perissinotto et al. 2002, Karakaş et al. 2012, Narancic et al. 2013, Santos et al. 2004, Rahman et al. 2010) (Table 2). Other Turkish studies show similar BMI values (Karakaş et al. 2012, Karadag et al. 2012) (Table 2). In particular, the BMI values of women in our country are quite high compared to other ethnic groups, suggesting malnutrition.

Table 2: Comparison of anthropometric measurements between studies.

\begin{tabular}{|c|c|c|c|c|c|c|c|c|c|c|c|c|}
\hline \multirow{3}{*}{ Author } & \multicolumn{6}{|c|}{ Male } & \multicolumn{6}{|c|}{ Female } \\
\hline & \multicolumn{2}{|c|}{$\underline{\text { Weight }(\mathrm{kg})}$} & \multicolumn{2}{|c|}{$\underline{\text { Height }(\mathrm{cm})}$} & \multicolumn{2}{|c|}{$\underline{\underline{\mathrm{BMI}}}{\underline{\left.\mathrm{kg} / \mathrm{cm}^{2}\right)}}^{2}$} & \multicolumn{2}{|c|}{$\underline{\text { Weight }(\mathrm{kg})}$} & \multicolumn{2}{|c|}{$\underline{\text { Height }(\mathrm{cm})}$} & \multicolumn{2}{|c|}{ 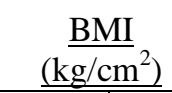 } \\
\hline & Mean & SD & Mean & $\mathrm{SD}$ & Mean & SD & Mean & SD & Mean & SD & Mean & $\mathrm{SD}$ \\
\hline $\begin{array}{l}\text { García et al. } \\
\text { (Mexico) }\end{array}$ & 70.3 & 12.3 & 163.2 & 8.5 & 26.4 & 4.4 & 62.7 & 11.6 & 152.6 & 7.5 & 26.8 & 4.4 \\
\hline
\end{tabular}




\begin{tabular}{|l|c|c|c|c|c|c|c|c|c|c|c|c|}
\hline $\begin{array}{l}\text { Perissinotto et al. } \\
\text { (Italy) }\end{array}$ & 72.6 & 10.7 & 162.7 & 7.2 & 26.4 & 3.7 & 63.8 & 13.1 & 152.2 & 7.5 & 27.6 & 5.7 \\
\hline $\begin{array}{l}\text { Rahman et al. } \\
\text { (Bangladesh) }\end{array}$ & 54.2 & 10.7 & 158.8 & 7.1 & 21.8 & 3.5 & 46.7 & 10.3 & 148.6 & 6.3 & 21.1 & 4.4 \\
\hline $\begin{array}{l}\text { Karakaş et al. } \\
\text { (Turkey) }\end{array}$ & 81.2 & 15.0 & 169.8 & 6.9 & 29.1 & 5.9 & 71.5 & 14.1 & 155.0 & 7.1 & 31.3 & 5.8 \\
\hline $\begin{array}{l}\text { Karadag et al. } \\
\text { (Turkey) }\end{array}$ & 78.3 & 10.1 & 165.2 & 4.4 & 28.7 & 3.2 & 73.0 & 12.2 & 153.0 & 5.1 & 31.2 & 4.7 \\
\hline Santos et al. (Chile) & 73.2 & 13.0 & 164.6 & 7.1 & 27.0 & 4.1 & 63.6 & 13.4 & 149.8 & 6.3 & 28.3 & 5.4 \\
\hline $\begin{array}{l}\text { Narancic et al. } \\
\text { (Croatia) }\end{array}$ & 78.1 & 12.9 & 167.8 & 7.1 & 27.2 & 4.2 & 65.4 & 12.2 & 152.7 & 6.4 & 28.0 & 4.7 \\
\hline $\begin{array}{l}\text { Present Study } \\
\text { (Turkey) }\end{array}$ & 76.6 & 14.2 & 163.1 & 4.9 & 27.6 & 2.8 & 75.2 & 14.0 & 151.0 & 4.0 & 31.0 & 4.0 \\
\hline
\end{tabular}

The WHR is now used to estimate relative increases in abdominal fat to determine the risk for developing non-insulin-dependent diabetes mellitus, dyslipidemias, arterial hypertension and coronary artery disease (García et al. 2007). According to the US Department of Health and Human Services (US-DHHS), the WHR cut-off points to detect obesity are $\geq 0.95$ and $\geq 0.80$ for males and females, respectively, similar to the values given by the WHO: $\geq 0.9$ and $\geq 0.85$, respectively (Jahanlou and Kouzekanani 2017). Individuals with values above these are at greater risk for cardiovascular disease morbidity and mortality (García et al. 2007). However, these cut-off points may not be appropriate for other nations. In our study, the mean WHR values were 0.91 in women and 0.97 in men, suggesting that all participants in our study are in the 'at risk' group. Garcia et al. (2007) studied 1968 elderly people (870 females and 1098 males) with an average age of 68.7 and found WHR values of 0.9 in females and 0.95 in males. Similarly, Garcia et al. (2007) showed that elderly Mexicans of both sexes were at risk. Compared with our study, the WHR values of the Mexican cohort were lower than those of the Turkish elderly. Perissinotto et al. (2002) studied 1710 males and 1544 females with an age range of 65-84 years, and the reported values of WHR were 0.97 and 0.94 , respectively, similar to our Turkish elderly cohort. The WHR values of Indian elderly individuals were not in the risk group: in their study on 147 elderly individuals, Reddy and Rao reported WHR values of 0.9 in males and 0.85 in females (Reddy and Rao 2010). Finally, Garcia et al. reported that MAC values were not different between sexes (females: $29.9 \pm 4.4 \mathrm{~cm}$; males: $29.9 \pm 4.0 \mathrm{~cm}$ ) (García et al. 2007).

In the general adult population, a waist circumference of $\geq 88 \mathrm{~cm}$ in women and $\geq 102 \mathrm{~cm}$ in men is a health risk indicator related to BMI and WHR, with a sensitivity greater than $94 \%$ and a specificity of $97 \%$. Therefore, this may be a good option for determining the BMI and WHR parameters quickly and reliably (García et al. 2007). The present study observed greater waist circumference than those established thresholds in both male and female elderly patients, as well as other studies in the literature (Perissinotto et al. 2002, Karakaş et al. 2012, Santos et al. 2004, Karadag 2012).

Circumferences of the extremities, especially MAC, have been found useful in evaluating the health and nutritional status of elderly persons and can also provide valuable information on muscle-related disability, physical function and mortality risk (Tsai and Chang 2011). Tsai and Chang studied 4191 elderly Taiwanese over the age of 53 and found the MAC to be $28.0 \pm 4.0 \mathrm{~cm}$ in women and $28.4 \pm 3.5 \mathrm{~cm}$ in men, concluding that MAC is a better predictor of follow-up mortality risk in the elderly than BMI. They interpreted low MAC values as a marker of mortality risk for the elderly under 75 years and normal MAC values as a mortality risk marker for the elderly over 75 years of age (Tsai and Chang 2011). Santos et al. (2004) reported that the MAC value was higher in females $(30.1 \pm 4.3 \mathrm{~cm})$ than in males $(29.8 \pm 3.7 \mathrm{~cm})$ in the Chilean elderly population. In a study conducted in 314 Croatian elderly over 85 years of age, the MAC values were very low in both males $(27.41 \pm 2.70 \mathrm{~cm})$ and females $(27.66 \pm 3.53 \mathrm{~cm})$ (Narancic et al. 2013). Enoki et al. found that the MAC levels of male participants $(24.3 \pm 4.1 \mathrm{~cm})$ of the $75-84$ age groups were significantly lower than Japanese norm; in particular, Japanese females had lower MAC $(23.1 \pm 4.5 \mathrm{~cm})$ than the normal Japanese reference values for age 80-85 (Enoki 2007). Rahman et al. (1998), in their study of 286 (164 females and 122 males) Malaysian elderly participants aged between 60 and 89, reported MAC values of $25.64 \pm 3.85 \mathrm{~cm}$ in females and $26.04 \pm 3.73 \mathrm{~cm}$ in males. These values of the Malaysian elderly are considered to be quite low compared to the values in the present study. The MAC values in both males $(27.1 \pm 3.3 \mathrm{~cm})$ and females $(28.5 \pm 3.9 \mathrm{~cm})$ found by Karakaş et al. were lower compared to those in our study (Karakaş et al. 2012). This difference can be attributed to regional changes in nutrition. The MAC data of women in our study were higher than those in the literature. 
Our handgrip strength data are consistent with previous reports in the literature, in that men are generally stronger than women (Pieterse et al. 2002, Chilima and Ismail 2001). Pieterse et al. (2002) reported hand grip strength values of $30.3 \pm 6.7$ and $22.3 \pm 5.1 \mathrm{~kg}$, respectively, in men and women aged 50-92 years. Similarly, Chilima and Ismail (2001) reported $28.0 \pm 5.9$ and $21.7 \pm 4.5 \mathrm{~kg}$ for men and women over 55 years, respectively. In our study, grip strength was very low, especially in females, and males in our study had lower grip strength than those in other studies in the literature. These low values are likely due to decreased muscle mass in the hand and forearm secondary to low protein nutrition and sedentary lifestyle.

In the general population, low muscle mass and high fat mass are associated with mortality (Enoki et al. 2007). Skinfold measurements have also been shown to correlate with body fat (Rahman et al. 1998). Triceps skinfold (TSF) thickness reflects subcutaneous fat (Enoki et al. 2007). Karakaş et al. (2012) reported that the TSF value was significantly higher in females $(27.11 \pm 8.2 \mathrm{~mm})$ than in males $(14.978 .8 \mathrm{~mm})$. Rahman et al. (1998) reported that the mean TSF values of elderly males and females between the ages of 60 and 89 years were $10.54 \pm 5.10$ and $16.35 \pm 7.12 \mathrm{~mm}$, respectively. Enoki et al. (2007) found that the TSF values of elderly Japanese were $15.5 \pm 9.5 \mathrm{~mm}$ in females and $14.3 \pm 9.4 \mathrm{~mm}$ in males. Narancic et al. (2013) also reported higher TSF values in elderly females $(18.02 \pm 7.34 \mathrm{~mm})$ than males $(10.56 \pm 4.78 \mathrm{~mm})$. It has been reported that the TSF values of women are higher than those of men in all studies conducted in the literature (Milanović et al. 2011). In contrast to other studies in the literature, the TSF values of males in our study were higher than those of females. In addition, both sexes had higher TSF values than those in other studies.

Nutrition is an important determinant of health status in the elderly people as it affects the ageing process. MNA is universally considered one of the most reliable instruments used to assess the nutritional status in the elderly (Donini et al. 2013). Donini et al. (2013) reported that $42.5 \%$ of elderly patients in nursing homes were malnourished, $43.4 \%$ were at risk of malnutrition, and $14.2 \%$ were normal. Rodrigues et al. (2014) studied 319 people over 65 years of age and reported that $13.8 \%$ of the participants were malnourished, $12.3 \%$ were at risk for malnutrition and $73.9 \%$ were normal. In the present study, we found that $4 \%$ of males and no female participants were malnourished, $20 \%$ of males and $32 \%$ of females were in the 'at risk' group, and $76 \%$ of males and $68 \%$ of females were normal.

Unlike other studies in the literature, we investigated the anthropometric parameters associated with the nutritional status. We found that only body weight, grip strength and WHR were significantly and positively correlated to MNA ( $\mathrm{p}<0.05)$.

\section{Conclusion}

In conclusion, we provided sex-specific distributions for many anthropometric measurements as reference values for the Turkish elderly population to detect individuals at greater risk for nutritional disorders. The association found between anthropometric measurements is consistent with the results of many longitudinal studies. Some anthropometric measurements such as BMI, waist circumference, hip circumference, waist-tohip ratio, triceps skinfold thickness and mid-arm circumference showed a high prevalence of obesity in women, which appears to be related to an increase in visceral fat. In addition, low values of muscle strength in women may lead to a decrease in muscle mass due to an increase in fat mass. Especially in the determination of the malnourished elderly, as our results show, body weight, the grip strength and WHR were found as supporting parameters for the MNA test.

\section{References}

[1] Bahat G, Tufan F, Saka B, Akin S, Ozkaya H, Yucel N, et al (2012) Which body mass index (BMI) is better in the elderly for functional status? Archives of Gerontology and Geriatrics 54: 78-81. (PIMD: 21628078).

[2] Başıüyük ÖG, Bektaş Y, Çınar Z, Ay F, Alan A (2017) Prevalence of malnutrition in nursing home residents. Journal of the Institute of Social Sciences of Ahi Evran University 3 (2): 339-348.

[3] Chilima DM, Ismail SJ (2001) Nutrition and handgrip strength of older adults in rural Malawi. Public Health Nutrition 4 (1): 11-17. (PIMD: 11255491).

[4] Daabiss M (2011) American Society of Anaesthesiologists physical status classification. Indian J Anaesth 55 (2): 111-115. (PIMD:21712864). 
[5] Donini LM, ScarDella P, PioMbo L,Neri B, Asprino R, Proietti AR, et al (2013) Malnutrition in elderly: social and economic determinants. The Journal of Nutrition, Health \& Aging 17 (1): 9-15. (PMID:23299371).

[6] Enoki H, Kuzuya M, Masuda Y, Hirakawa Y, Iwata M, Hasegawa J, et al (2007) Anthropometric measurements of mid-upper arm as a mortality predictor for community-dwelling Japanese elderly: The Nagoya Longitudinal Study of Frail Elderly (NLS-FE). Clinical Nutrition 26: 597-604. (PIMD:17669559).

[7] García SS, Peña CG, López MXD, Teresa JC, Alma RCN, Sandra RB (2007) Anthropometric measures and nutritional status in a healthy elderly population. BMC Public Health 7 (2): 1-9. (PMID:17201919).

[8] Guigoz Y, Vellas B, Garry PJ (1996) Assessing the nutritional status of the elderly: the mini nutritional assessment as part of the geriatric evaluation. Nutrition Reviews 54 (1): 59-65. (PIMD:8919685).

[9] Jahanlou AS, Kouzekanani K (2017) A comparison of waist-to-hip ratio cut-off points in a large sample of southern Iranian adults with two standard procedures and Asian studies. Shiraz E-Med J 18 (6): 1-8. doi: 10.5812/semj.13796

[10] Karadag B, Ozturk AO, SenerN, Altuntas Y (2012) Use of knee height for the estimation of stature in elderly Turkish people and their relationship with cardiometabolic risk factors. archives of gerontology and geriatrics 54: 82-89. (PMID:21185093).

[11] Karakaş S, Dişcigil G, Bilgin MD, Tekin N, Özlem S (2012) Evaluatıon of anthropometric measurements of a group of elderly from Turkey. Turkish Journal of Geriatrics 15 (4): 403-408.

[12] Milanović Z, Pantelić S, Trajković N, Sporiš G (2011) Basic anthropometric and body composition characteristics in an elderly population: a systematic review. Physical Education and Sport 9 (2): 173182.

[13] Narancic NS, Milicic J, Tomas E, Petranovic MZ, Juric TS, Roksandic ST (2013) Anthropometric indices of nutritional status in croatian oldest old: new equations to predict height and weight. Periodicum Biologorum 115 (4): 483-489.

[14] Perissinotto E, Pisent C, Sergi G, Grigoletto F, Enzi G (2002). Anthropometric measurements in the elderly: age and gender differences. British Journal of Nutrition 87: 177-186. (PIMD:11895170).

[15] Pieterse S, Manandhar M, Ismail S (2002) The association between nutritional status and handgrip strength in older Rwandan refugees. European Journal of Clinical Nutrition 56: 933-939. (PIMD:12373611).

[16] Rahman A, Moni MA, Ahmed K, Islam S, Haque A (2010) Anthropometric profile of the urban senior citizens. Ibrahim Med. Coll. J. 4 (2): 59-62.

[17] Rahman SA, Zalifah MK, Zainorni, MJ (1998) Anthropometric measurements of the elderly. Mal J Nutr 4:55-63. (PIMD:22692341).

[18] Reddy KK, Rao AP (2010) Nutritional status and impaired functional ability among the elderly. The Open Anthropology Journal, 3: 192-199.

[19] Republic of Turkey Ministry of Health (2017) Health Statistics Yearbook 2016 https://dosyasb.saglik.gov.tr/Eklenti/13160,sy2016enpdf.pdf?0

[20] Rodrigues RAS, Espinosa MM, Melo CD, Perracini MR, Fett WCR, Fett CA (2014) New values anthropometry for classification of nutritional status in the elderly. J Nutr Health Aging 18 (7): 65561. (PIMD:25226103).

[21] Saka B, Kaya O, Ozturk BG, Erten N, Karan MA (2010) Malnutrition in the elderly and its relationship with other geriatric syndromes. Clinical Nutrition 29: 745-748. (PMID: 20627486).

[22] Santos JL, Albala C, Lera L, García C, Arroyo P, Pérez-Bravo F,et al (2004) Anthropometric measurements in the elderly population of Santiago, Chile. Nutrition 20: 452- 457. (PIMD: 15105033).

[23] Tsai AC, Chang TL (2011) The effectiveness of BMI, calf circumference and mid-arm circumference in predicting subsequent mortality risk in elderly Taiwanese. British Journal of Nutrition 105: 275281. (PIMD: 21129232).

[24] Vetta F, Ronzoni S, TaglieriG, Bollea MR (1999) The impact of malnutrition on the quality of life in the elderly. Clinical Nutrition 18 (5): 259-267. (PIMD:10601532). 